\title{
20 Interviews With Attempted Suicides
}

Turning Points (De Leo, 2010) presents us with moving written accounts from nine people who attempted to kill themselves, but who survived. All of them but one were happy to have survived. The question asked in this chapter is whether the essays written by these individuals provide clues to the suicidal mind.

\subsection{The Attempters}

\subsubsection{Trevor}

Trevor was a young man who became a drug and alcohol abuser. The woman he loved rejected him for another man, and his substance abuse worsened. He confided to no one. One night, he was drinking heavily and smoking dope, and he went home to change his clothes in order to go to a disco. He sat down and thought that he did not want to go out or do anything anymore. He got his roommate's shotgun and ammunition and waited for his friends to come by. He sat down and wrote a suicide note: Tell Mum and Dad that I'm sorry and I love them. He squeezed the trigger, but he had left the safety on. He tried again and, as he squeezed the trigger, changed his mind and tried to pull his head out of the way, but he shot much of the front of his head off. De Leo noted that Trevor's account was rather "dry," and there is a lack of premeditation. There is also ambivalence as he waits for his friends to stop by. But Trevor seems to have little ability to self-monitor - to tell us what his mood and thoughts were.

\subsubsection{Anna}

Anna was sexually abused as a child by several men - neighbors, family friends and her grandfather. The abuse by her grandfather left her confused for she loved him and felt close to him but she knew what he was doing was wrong. He stopped abusing Anna when she was twelve, and he died two years later.

On the day that he died, Anna was stoic, "numb to the grief around me." She had been fighting with her parents to be allowed to go away with friends. Her relationship was "tumultuous" with her mother and distant with her step-father. Her brother and sister-in-law were "always there for me, but I felt such a burden on them." She felt hopeless and experienced despair. She went and got her grandfather's medications and ingested them all. "I am hopeless, bad at school, I can't get on with my parents, I am a burden to my support people, I cannot take another moment of this anguish. I can’t cope anymore, I hate my life, I have nothing to live for” (p. 64). 
Anna, therefore, illustrates common elements of the suicidal mind - psychological pain, hopelessness, and a sense of being a burden.

\subsubsection{Alessa}

Alessa was born into a wealthy family, but with a dysfunctional mother who could not cope with life and a father who was gone on business much of the time. Her mother made several suicide attempts with overdoses and, when Alessa was fifteen, she found her mother on the floor having tried to cut her throat. Alessa married, but her husband physically abused her and Alessa left him. Two months later she gave birth to a child with Down's syndrome. Alessa had a psychotic breakdown.

Alessa's mother changed dramatically at that time and became a good surrogate mother to her grandson, while Alessa continued to have symptoms of schizophrenia and became a drug addict. Eventually, Alessa recovered to some extent and got a job as a secretary when, one Easter, she decided it was time to die. "It happened all of a sudden....Basically, I wasn't doing badly. Yet that Saturday afternoon I decided that my hour had come, that the time was right, and that there was no point in going on' (p. 84). "I was suddenly overcome by the conviction that everything had been horrible and that I could no longer do anything with passion or hope. I was overcome by a sense of suffocating anxiety....My head was spinning and I felt I couldn't breathe anymore" (p. 85). She swallowed two laundry bottles of stain remover.

What is interesting here is the anxiety attack that immediately preceded her suicide attempt. She swallowed the poison in the midst of this emotion.

\subsubsection{Sergio}

Sergio, a father, felt responsible for letting his son drive a tractor when he was only twelve years old, which crashed and crippled the young boy. Sergio never recovered from the guilt, and his life became full of pain, guilt and a sense of oppression. In the months before his suicide attempt, this became unbearable. He could not sleep and began to drink heavily.

Sergio did not remember much of the day he tried to kill himself, but he remembered climbing the silo, shaking and crying. He thought that his pain would soon be over. But as soon as he jumped, he decided that he did not want to die. He reoriented himself while falling and damaged only his feet and ankles. 


\subsubsection{Sandro}

Sandro became a concert pianist and married young. Although Sandro liked playing in bars, performing in concerts caused great tension for him. He began to drink, and eventually his wife left him. He was an alcoholic, with no job and no confidantes. He decided to kill himself.

He was sleeping only about two hours each night. He was tense and irritable, and yelling at his mother. One night at 2 am, he drove to his ex-wife's apartment and tried to kill himself with car exhaust. He wanted his ex-wife to see his corpse the next day. As he sat in the car, he drank some cognac and began writing a suicide note to his parents and to his ex-wife, mostly to her. He described the letter as full of accusations, anger, and threats.

\subsubsection{Fabrizio}

Fabrizio was diagnosed as having bipolar affective disorder at the age of 22. He lived in the countryside with his parents (his father was a policeman) and an uncle who shot himself at the age of 55. After his fourth or fifth admission for depression, Fabrizio began to think about suicide. During one hospitalization, Fabrizio met a woman whom he liked very much but who disappeared out of his life. During his last admission, he found out that she had hung herself. After his discharge he went home, got his father's gun and went into the basement. "I think my heart was beating fast. Rather strangely, while my head was in complete turmoil, my movements were correct and coordinated" (p. 115).

Again, like Alessa, Fabrizio reported only anxiety. Interestingly, he has two models for his choice - his uncle and the woman he liked - and he attempted suicide immediately after release from the psychiatric hospital, a common time for suicides in psychiatric patients.

\subsubsection{Lucia}

Lucia was married with two children. Her father, suffering from a bipolar disorder, killed himself using hanging when she was 27 . His body was discovered by her younger brother. Her marriage was not good. There was no love and little sex. On the day, Lucia jumped from the third floor window of her apartment, she was tired from her work that day as a school teacher, and she reported a sensation of never-ending anxiety which she had been living with for some time.

Her husband, who was director of a museum, was tense that day and wanted Lucia to accompany him to a museum reception at which the Mayor was attending. There was tension between them in the car when she asked him to wait for her to go 
upstairs to the toilet. "I climbed the stairs again. It was suffocating inside there. My head was so heavy and my legs grew increasingly weaker.....I opened the door of the balcony....I didn't look down, I didn't hesitate - I just closed my eyes and I jumped....I thought that I was going to put an end to everything that was horrible and senseless. I was going to free myself, forever” (p. 124).

\subsubsection{Umberto}

Umberto was an old man and had to use a wheelchair. His wife had died of cancer fifteen years earlier, and his four children were grown up. His two daughters lived nearby but, “Even if I have cancer, I don’t want my daughters to sacrifice their lives to remain close to me" (p. 130). Umberto spent time with a friend who had been crippled in a car wreck that killed his wife. Umberto secretly stole barbiturate pills from his friend over a period of months. He thought about using them to "reach" his wife whenever he chose to die, yet he did not believe in an afterlife. "What was there to live for?" He chose to overdose on the anniversary of his wife's death. He wrote notes to his children and to his friend. Worried that his friend would imitate him, Umberto wrote that, "my condition would have rapidly worsened anyway. More suffering, more medical visits, more interventions. More money spent, more assistance, more concern from my children. Better to end it as soon as possible” (p. 134). Umberto took the overdose and, in contrast to those above who reported being anxious in the moments leading up to the attempts, Umberto reported being calm.

\subsubsection{Maria}

Maria was an elderly lady, in a nursing home, who talked to Diego rather than writing. Maria suffered from a bipolar disorder and had attempted suicide in the past. Her life had been traumatic, with emigrations, the death of her husband and the suicides of her two sons. She jumped from the window of her apartment and suffered a spinal injury that left her paraplegic. "I don't know why I did it....and if someone would try to explain it to me, I would probably not believe it. The only thing that I remember is the tension that was devouring me, the incredible disquiet that I felt. I was confused. I could not clearly think about anything....I didn't want to suffer any more...... did want to stop that tension, to put an end to that unbearable suffering. I am not sure if you really know what anxiety is, that particular anxiety. It is like a devil that bites you inside, that squeezes your lungs. You cannot breathe, you really cannot breathe" (pp. 147-148.). 


\subsection{Discussion}

An interesting feature of these accounts is how little insight the people had into their mental state and their psychodynamics. They do illustrate several features wellknown to suicidologists, such as escape from mental and physical pain (Sergio and Maria), anger (Sandro), hopelessness and a feeling of being a burden (Anna), and suicide soon after discharge from a psychiatric hospital (Fabrizio).

What is noteworthy is the anxiety noted by four of the individuals, Alessa, Fabrizio, Lucia and Maria. Alessa, Lucia and Maria all talk of suffocating and not being able to breathe any more, and two of them (Lucia and Maria) indicate that the anxiety was long-standing and not simply a result of the decision to kill themselves. In fact, Maria tried to die to get away from the anxiety. Anxiety has not been mentioned to any great extent in analyses of suicidal behavior. The focus has been on depression instead. These accounts indicate that clinicians should evaluate clients who are potentially suicidal for anxiety as well as depression and hopelessness.

Two other features also stand out. Four of the individuals had close relatives or friends who completed or attempted suicide, and it is well-known that having a significant other die from suicide is a risk factor for suicide. Second, five of the attempts were impulsive (Alessa, Fabrizio, Lucia, Maria and Trevor). Impulsive suicidal acts are very difficult for clinicians to predict and prevent. 